\title{
Prevalence and predictors of work related respiratory symptoms in workers exposed to organic dusts
}

\author{
J C G Simpson, R M Niven, C A C Pickering, A M Fletcher, L A Oldham, \\ $\mathrm{H} M$ Francis
}

\begin{abstract}
Objectives-The aims of this study were to document the prevalence of work related upper and lower respiratory tract symptoms in workers exposed to organic dusts and to identify variables predictive of their occurrence.

Methods-A cross sectional survey with an administered questionnaire (a previously validated adaptation of the Medical Research Council (MRC) respiratory questionnaire) was performed. Symptoms were classified as work related by their periodicity. Demographic data, smoking habits, and occupational histories were recorded. Personal exposures to dust and endotoxin were measured and individual subjects ascribed an exposure value specific to occupation, site and industry. Cox's regression techniques were used to identify variables predictive of work related upper and lower respiratory tract symptoms. Information was stored using Dbase 3 and analysed with SPSS.
\end{abstract}

Results-1032 Workers (93\% of the target population) were studied in nine different industries. The highest prevalences of work related lower respiratory tract symptoms $(38.1 \%)$, upper respiratory tract symptoms $(45.2 \%)$, and chronic bronchitis (15.5\%) were found among poultry handlers. White workers were significantly more likely to complain of upper and lower respiratory tract symptoms. An individual in the swine confinement industry had a symptom complex compatible with byssinosis. Increasing current personal exposures to dust or endotoxin were found to be predictive of upper and lower respiratory tract symptoms, chronic bronchitis, and byssinosis. In a univariate analysis a relation between current exposures and the organic dust toxic syndrome was found. Present smoking and previously documented respiratory tract illness were significantly predictive of work related lower respiratory tract symptoms. Women were more likely to report work related upper respiratory tract symptoms.

Conclusions-People exposed to organic dusts may have a high prevalence of work related respiratory tract symptoms which are related to dust exposures and smoking habits. Action should be taken to reduce exposures to dust and endotoxin and stop- ping smoking should be promoted among workers exposed to organic dusts to reduce morbidity.

(Occup Environ Med 1998;55:668-672)

Keywords: respiratory symptoms; organic dusts; endotoxin

Many people are exposed to organic dusts during their work. These dusts are complex, containing material derived from both animals and vegetables. Exposures are known to be aetiologically important in several diseases: occupational asthma, ${ }^{1}$ allergic alveolitis, ${ }^{2}$ byssinosis, chronic airflow limitation, ${ }^{3}$ chronic bronchitis, ${ }^{4}$ and the organic dust toxic syndrome. ${ }^{5}$

Ubiquitous contaminants of organic dusts are endotoxins. Endotoxins are derived from the cell wall of gram negative bacteria. They are recognised as potent biological agents, much of their activity caused by the lipid A component. ${ }^{6}$ Experimental inhalational exposures in humans are associated with both symptomatic and physiological changes. ${ }^{78}$ Their importance in the aetiology of occupationally related respiratory disease, byssinosis, ${ }^{9}$ humidifier fever, ${ }^{10}$ and organic dust toxic syndrome ${ }^{11}$ has been highlighted. Also their possible role in the severity of asthma has been suggested. ${ }^{12}$

Investigators have used different methods to assess exposures and the prevalence of respiratory morbidity. This means that comparisons of the prevalence of work related respiratory tract symptoms and the effects of organic dusts (contaminated with endotoxins) across different industries are not possible with the existing data. In this study a single centre used standardised methods to evaluate personal exposures to dust and endotoxin and prevalence of respiratory morbidity. With this information valid comparisons for the prevalence of work related symptoms have been made between industries, and important aetiological factors have been elucidated.

\section{Methods}

A cross sectional survey of workers exposed to organic dusts in the United Kingdom was performed over a 12 month period. The cohort comprised people working in the textile industry (cotton spinning and weaving, and wool scouring and combing), agriculture (mushroom cultivation and swine confinement), grain handling, animal feed processing, saw mills, and poultry catching or shackling gangs. 
Table 1 Demographic data

\begin{tabular}{lccllllc}
\hline Industry & $\begin{array}{l}\text { Sites } \\
(n)\end{array}$ & $\begin{array}{l}\text { Interviewed } \\
(n)\end{array}$ & $\begin{array}{l}\text { Target } \\
\text { population } \\
(\%)\end{array}$ & $\begin{array}{l}\text { Worker } \\
\text { smokers } \\
(\%)\end{array}$ & $\begin{array}{l}\text { Mean } \\
\text { age }(y)\end{array}$ & $\begin{array}{l}\text { Male } \\
(\%)\end{array}$ & White (\%) \\
\hline Mushroom & 2 & 122 & 93.1 & 52.5 & 32.9 & 32 & 98.4 \\
Swine & 11 & 43 & 100 & 32.6 & 33.9 & 97.7 & 100 \\
Grain & 3 & 69 & 97.2 & 31.9 & 44.8 & 92.8 & 98.6 \\
Poultry & 8 & 84 & 96.6 & 63.1 & 30.2 & 100 & 100 \\
Saw mill & 6 & 101 & 98.1 & 41.6 & 35.4 & 100 & 100 \\
Cotton & 2 & 226 & 83 & 44.2 & 44.3 & 74.3 & 65.5 \\
Wool & 1 & 139 & 92.1 & 38.1 & 44.8 & 99.3 & 48.9 \\
Animal feed & 1 & 34 & 100 & 55.9 & 38 & 100 & 100 \\
Weaving & 2 & 214 & 95.6 & 47.2 & 38.1 & 63.1 & 95.8 \\
Total & 36 & 1032 & 93 & 45.3 & 39.1 & 78 & 84.4 \\
\hline
\end{tabular}

Table 2 Prevalence (\%) of work related symptoms of the respiratory tract

\begin{tabular}{llllll}
\hline Industry & $\begin{array}{l}\text { LRTS } \\
(\%)\end{array}$ & $\begin{array}{l}\text { URTS } \\
(\%)\end{array}$ & $\begin{array}{l}\text { Chronic } \\
\text { bronchitis (\%) }\end{array}$ & Byssinosis (\%) & ODTS (\%) \\
\hline Mushroom & 14.8 & 32.8 & 1.6 & 0 & 2.5 \\
Swine & 23.3 & 34.9 & 9.3 & 2.3 & 0 \\
Grain & 20.3 & 40.6 & 5.8 & 0 & 4.3 \\
Poultry & 38.1 & 45.2 & 15.5 & 0 & 5.9 \\
Saw mill & 12.9 & 20.8 & 5 & 0 & 0 \\
Cotton & 15 & 20.4 & 4.4 & 4 & 1 \\
Wool & 8.6 & 10.1 & 2.9 & 0 & 0 \\
Animal feed & 11.8 & 38.2 & 0 & 0 & 0 \\
Weaving & 15.4 & 29.4 & 2.3 & 0 & 1.3 \\
Total & 16.5 & 26.9 & 4.6 & 1 & \\
\hline
\end{tabular}

Approaches were made at each site to senior management, safety officers, workers' representatives, and occupational health and hygiene departments where applicable. The nature of the survey was explained and cooperation from these departments obtained.

Workers were invited to participate in the survey and if agreeable answered an administered questionnaire. The questionnaire used was an adapted version of the Medical Research Council (MRC) respiratory questionnaire. ${ }^{13}$ The questionnaire has been previously validated and used for several years by the department. ${ }^{14}$ It is designed to collect demographic data, an occupational history, upper and lower respiratory symptoms (including any work related relations), information on previous respiratory illness, and a detailed smoking history. Symptoms were designated as work related if they improved on holidays or days away from work. The questionnaire was administered by one of two investigators and the information was stored using Dbase 3 software directly on to a portable computer.

The lower respiratory tract symptoms recorded were cough, phlegm, shortness of breath, wheeze, and chest tightness. From this information it was possible to identify people with symptom complexes compatible with chronic bronchitis (defined as a cough producing sputum for most days for 3 months of $\geqslant 2$ consecutive years) and byssinosis (defined as chest tightness worse on the first working day, improving as the week progressed). People reporting one or more lower respiratory tract symptoms with a work related periodicity were identified as a group (LRTS). The upper respiratory tract symptoms recorded were eye and nasal irritation. People with one or more of these upper respiratory tract symptoms with a work related periodicity were identified as a group (URTS). The organic dust toxic syndrome was identified by people reporting recurrent episodes of at least two of the follow- ing symptoms: fever; shivering; malaise; weakness; and joint or muscle pains.

A representative sample of the workforce at each site was selected to record personal total dust exposures during a typical workshift. These results have been reported in detail previously..$^{15}$ To normalise the data, the natural log for both current endotoxin and dust exposures were ascribed to individual people. Each occupational group specific to site and room were accredited with the average value for the samples taken. When only one sample existed this value was allocated to other people in that occupational group, work room, and site. For 32 people $(3.1 \%$ of the population) no exposure value was obtained because people in that specific occupation were either unwilling, unable, or unavailable to wear a sampling device. These people were excluded from the analysis of exposure effects.

All data was stored with Dbase 3 software and statistical analysis was performed with SPSS. The prevalence of symptoms are expressed as percentages. A two stage forward step Cox's regression model with the likelihood ratio removal criteria was used for each dependent variable (LRTS, URTS, chronic bronchitis, byssinosis and organic dust toxic syndrome) examined. A two stage model was used because of the relation between dust, endotoxin, and industry. Specific industries tended to have both high dust and endotoxin concentrations. Seven industry groups were used with swine and poultry workers as well as grain handlers and animal feed processors being collapsed into single groups because of small numbers and workers were thought to have similar exposures. Industry in the model was used as a categorical variable and comparisons made to the weaving industry where both the lowest dust and endotoxin exposures were measured. The independent variables entered in the first stage were sex (male or female), age (y), ethnic group (white or non-white), previous occupational dust exposure (yes or no), time spent in current industry (y) and room (y), the wearing of respiratory protection (yes or no), a history of physician diagnosed asthma, hay fever, or bronchitis (all yes or no) and smoking (present smoking (yes or no) and pack-years). Bronchitis was not entered in the model for work related chronic bronchitis. At the second stage, industry and the naturally logged exposure variables for dust and endotoxin were entered. The significance of predictive variables are given with the prevalence rate ratios (PRRs) and 95\% confidence intervals (organic dust toxic syndrome).

\section{Results}

A total of 1032 people were surveyed in nine different industries working on 36 different sites. This represented $93 \%$ of the total target population. The industries surveyed, the number of sites, numbers interviewed, and the percentage of the target population are shown in table 1 . The population was predominantly male $(78 \%)$ and white $(84.4 \%)$ with a mean age of 39.1 (SD 13.2) years. The highest 


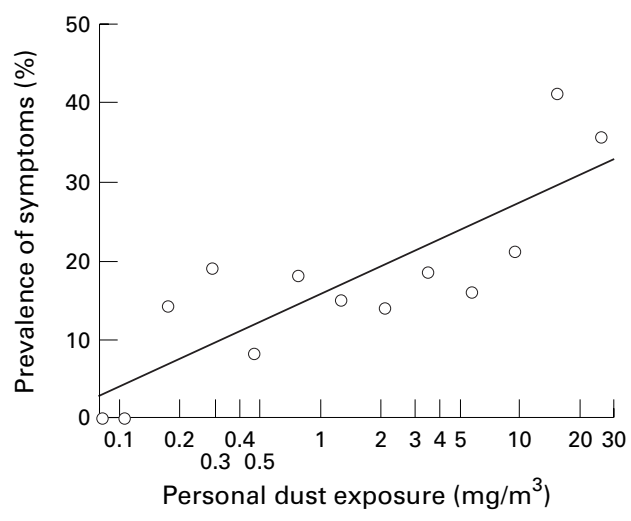

Figure 1 Relation between dust exposure $\left(\mathrm{mg} / \mathrm{m}^{3}\right)$ plotted on a log scale and the prevalence of work related LRTS expressed as the percentage of the workforce affected.

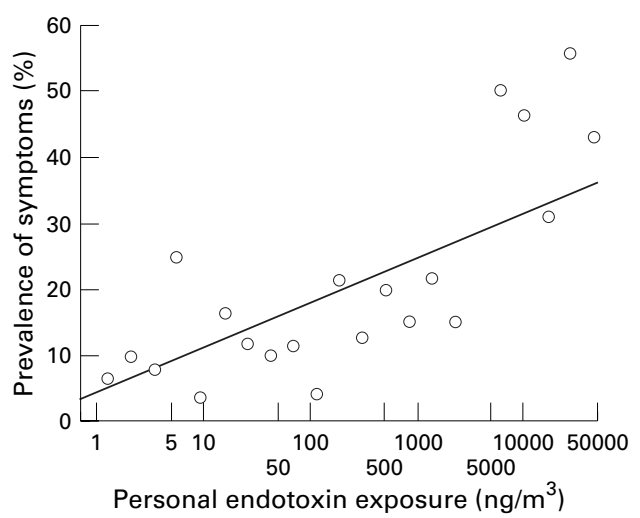

Figure 2 Relation between endotoxin exposures $\left(\mathrm{mg} / \mathrm{m}^{3}\right)$ plotted on a log scale and the prevalence of work related LRTS expressed as the percentage of the workforce affected.

prevalence of current smoking was found in poultry workers $(63.1 \%)$ and the lowest in grain handling $(31.9 \%)$.

The prevalence of work related symptoms is shown in table 2 . The highest prevalence of work related LRTS was recorded in the animal handling industries (38.1\% poultry and $23.3 \%$ swine). Work related chronic bronchitis was most commonly found in poultry handlers $(15.5 \%)$. A symptom complex compatible with byssinosis was found among cotton spinners $(4 \%)$, and in a swine confinement worker. Upper respiratory tract symptoms were found most commonly among poultry $(45.2 \%)$ and grain $(40.6 \%)$ handlers. The lowest prevalence of symptoms was found in the wool industry

Table 3 Predictor variables for work related LRTS with prevalence rate ratio $(95 \%$ CI)

\begin{tabular}{|c|c|c|c|}
\hline Variable & $p$ Value & $\begin{array}{l}\text { Prevalence rate } \\
\text { ratio }\end{array}$ & $(95 \% C I)$ \\
\hline History of asthma & $<0.001$ & 2.08 & (1.38 to 3.14 ) \\
\hline History of bronchitis & $<0.001$ & 2.03 & (1.35 ot 3.05$)$ \\
\hline Present smoking & $<0.001$ & 1.79 & (1.30 to 2.47$)$ \\
\hline Higher exposure to dust or endotoxin & $<0.001$ & 1.11 & (1.05 to 1.17$)$ \\
\hline Ethnic group (white) & $<0.05$ & 2.12 & (1.17 to 3.83$)$ \\
\hline
\end{tabular}

Table 4 Predictor variables for work related URTS with prevalence rate ratio (95\% CI)

\begin{tabular}{llll}
\hline Variable & p Value & $\begin{array}{l}\text { Prevalence rate } \\
\text { ratio }\end{array}$ & (95\% CI) \\
\hline Ethnic group (white) & $<0.001$ & 2.40 & $(1.43$ to 4.01$)$ \\
Sex (female) & $<0.001$ & 2.12 & $(1.60$ to 2.82$)$ \\
Higher exposure to dust or endotoxin & $<0.001$ & 1.28 & (1.16 to 1.42$)$ \\
\hline
\end{tabular}

for both grouped categories-LRTS (8.6\%) and URTS $(10.1 \%)$.

The results for the hygiene measures have been presented elsewhere in detail, ${ }^{15}$ however two points are worth highlighting. Firstly, the mean (range) sampling rate across the population was $25.1 \%(17 \%-63 \%)$. This was determined by the number of sites visited for each industry, the number of employees at each site, and the diversity of exposures (task related) found. Secondly, a significant correlation $(\mathrm{r}=0.7, \mathrm{p}<0.001)$ was found between the collected dust and measured endotoxin. This meant that the separate effects of these two variables could not be elucidated in the Cox's regression analysis and these are treated as a single variable (dust and endotoxin) in the models. The most significant of these two variables was entered at the second stage of the analysis.

The relation between exposures to dust and endotoxin and the occurrence of work related respiratory symptoms are shown in figures 1 and 2 respectively. People were grouped according to incremental dust or endotoxin exposures. The groupings were plotted on the $\mathrm{x}$ axis with a $\log$ scale. For each group the percentage prevalence of work related lower respiratory tract symptoms was calculated and plotted on the y axis. It can be appreciated that a relation exists between increasing exposures to dust and endotoxin and the prevalence of work related lower respiratory tract symptoms. For each industry with the exception of the weaving and mushroom industries (where the lowest exposures were found), workers in the LRTS group had non-significantly higher mean dust and endotoxin exposures than asymptomatic workers.

To further examine variables predictive of work related LRTS, URTS, chronic bronchitis, and byssinosis forward step Cox's regression techniques were used. Tables 3-6 present the variables found to be independently predictive of a person reporting LRTS, URTS, work related chronic bronchitis, and byssinosis, respectively. The significance and the prevalence rate ratios (PRRs) (95\% CIs) are quoted. For organic dust toxic syndrome the regression model became unstable on the entry of industry in the second stage. Univariate analysis found the following significant PRRs; increasing endotoxin exposure $(\mathrm{p}=0.005, \mathrm{PRR} 1.33$ (CI 1.09 to 1.63)), increasing dust exposure ( $p=0.019$ PRR 1.65 (CI 1.09 to 2.50)) and physician diagnosed bronchitis $(\mathrm{p}=0.05 \mathrm{PRR}$ 3.70 (CI 1.02 to 13.44 )).

For LRTS (table 3) smoking habits, previous respiratory illness, increasing years worked in the industry, and higher exposures to dust or endotoxin were predictive of symptoms. Working in the wool industry was predictive of a lower prevalence of LRTS. Women with higher exposures to dust or endotoxins were found to be most likely to be affected by URTS (table 4). Not surprisingly, the occurrence of work related chronic bronchitis (table 5) was predicted by smoking, a history of physician diagnosed bronchitis, and increasing exposure to dust or endotoxins. Byssinosis (table 6) was 
Table 5 Predictor variables for work related chronic bronchitis with prevalence rate ratio (95\% CI)

\begin{tabular}{llll}
\hline Variable & p Value & $\begin{array}{l}\text { Prevalence rate } \\
\text { ratio }\end{array}$ & (95\% CI) \\
\hline Higher exposure to dust or endotoxin & $<0.001$ & 1.19 & $(1.08$ to 1.31$)$ \\
Present smoking & $<0.005$ & 2.80 & $(1.47$ to 5.32) \\
Ethnic group (white) & $<0.05$ & 8.12 & (1.12 to 58.98) \\
\hline
\end{tabular}

Table 6 Predictor variables for byssinosis with prevalence rate ratio and 95\% confidence interval

\begin{tabular}{llll}
\hline Variable & p Value & $\begin{array}{l}\text { Prevalence rate } \\
\text { ratio }\end{array}$ & (95\% CI) \\
\hline Increasing industry (y) & $<0.001$ & 1.11 & $(1.05$ to 1.17$)$ \\
Increasing exposure to dust or endotoxin & $<0.005$ & 1.78 & $(1.22$ to 2.61$)$ \\
Sex (female) & $<0.01$ & 6.44 & $(1.66$ to 25.04$)$ \\
\hline
\end{tabular}

found to be more common in men with higher exposure to dust or endotoxin and increasing years in the industry. The organic dust toxic syndrome for univariate analysis was related to current exposures to dust or endotoxin but the effects of industry could not be adjusted for.

\section{Discussion}

A cross sectional study is always going to be open to bias from the healthy worker effect, with an underestimation of the true effects because data are collected from a survivor population. A prospective study following up leavers would be required to overcome this bias. In the current study, a sampling rate of $93 \%$ of the target population represents an epidemiologically valid sample for the study design. Grouped categories of LRTS and URTS are reported; the highest and lowest percentage prevalences of both were found in poultry handling and wool scouring respectively. It was postulated at the outset that exposures to dust or endotoxins were important in the aetiology of symptoms. In the cohort studied, industries in which the most contaminated dusts were found had the highest dust exposures and vice versa. Undoubtedly this was an important factor in being unable to disentangle the separate effects of endotoxin and dust. For much of the analysis the single variable of dust or endotoxin has been used. The findings of figures 1 and 2 which show symptom prevalence and grouped incremental exposures to dust or endotoxin, and the Cox's regression models, support the hypothesis that exposures are important in the aetiology of work related upper and lower respiratory tract symptoms. The study was not designed to look for a threshold or no effect level. However, the current study shows that workers are experiencing work related respiratory tract symptoms attributable to their current exposures to dust.

The separate industry groups were too small to allow for a meaningful analysis within the industry. The study found non-significant but consistent (with the exception of weaving and mushroom cultivation where the lowest dust and endotoxin exposures were found) higher mean exposures to dust and endotoxin in workers with symptoms than in their asymptomatic counterparts. This could be interpreted as indicating that industry specific exposures may be more appropriate than a single univer- sal exposure level for endotoxin. This would recognise the fact that organic dusts are diverse in nature, containing a wide range of potentially pathogenic material and the different postulated mechanisms of endotoxin action (direct and facilitatory). ${ }^{16}$

The Cox's regression model for LRTS also identified, as might be expected, current smoking and previously diagnosed asthma or bronchitis as being independently predictive. The white population was found to have more symptoms than their non-white counterparts not only for LRTS but for URTS and work related chronic bronchitis. The protective effect may reflect language problems in administering the questionnaire (although steps were taken to overcome this by using other language fluent workers to translate when appropriate) or simply that non-white people are less likely to report symptoms than are white people. ${ }^{417}$

The finding of an excess of eye or nasal symptoms in female workers has been reported previously. ${ }^{1418}$ Whether this is a true effect, with women more susceptible to experience such symptoms, or alternatively that women are more open in reporting symptoms that may be considered trivial by the male population is unclear. Most of the women in the current study were in the textile industry and it is possible that these workers are exposed to different dusts with a greater level of large particles than their male counterparts working in the earlier processes.

As well as documenting symptom prevalence, attempts have been made with an adapted version of the MRC questionnaire to identify three work related (improving on rest days or holidays) diseases. Firstly, work related chronic bronchitis, most commonly reported by white people and poultry catchers or shacklers $(15.5 \%)$, was found to be related to exposure to dust or endotoxin independent of smoking habits. The importance of dust exposures, independent of smoking, in the aetiology of chronic bronchitis in other industries is recognised. ${ }^{4}{ }^{19-21}$

Secondly, byssinosis was found among cotton spinners. Most of the workers identified had been assessed by the medical boarding panel and had been compensated for their disease. The finding of a worker in the swine confinement industry with a compatible symptom complex is of interest. Cases have been reported outside the conventionally recognised cotton, jute, and flax industries. ${ }^{22}$ The worker in this instance was a lifelong non-smoker with $>20$ years in the industry. Also, his vitalograph (a single measurement made during his workshift) was obstructed with reduced lung volumes. The Cox's regression model supports the hypothesis that dust contaminated with endotoxin is important in the aetiology of the condition. Both increasing dust or endotoxin and years in the industry were found to be independently predictive. No relation with smoking was found.

Finally, the organic dust toxic syndrome was identified by reporting two or more symptoms commonly associated with the syndrome. ${ }^{7}$ However, the symptoms described for the 
organic dust toxic syndrome have some overlap with those found in extrinsic allergic alveolitis and a questionnaire alone may not be sufficiently sensitive to distinguish the two conditions. This may account for the cases identified in the mushroom cultivation industry, in which extrinsic allergic alveolitis is well recognised. ${ }^{23}$ A satisfactory multiple regression analysis was not possible due to the effects of industry destabilising the model. The univariate analysis showing a relation between current personal exposures and organic dust toxic syndrome should be interpreted cautiously as the effects of confounders have not been accounted for (perhaps most relevant industry). The absence of the organic dust toxic syndrome in most workers despite high levels of exposures may also be interpreted as casting doubt on the importance of endotoxins in the aetiology. ${ }^{5}$ The agent or agents responsible for this syndrome (which may represent several different pathological processes) remain to be identified.

In conclusion, the current study has, as well as providing comparative prevalence data for work related upper and lower respiratory tract symptoms, provided further evidence that organic dusts contaminated with endotoxin are important in the aetiology of respiratory morbidity. The finding that smokers and workers with previously diagnosed respiratory illness had an increased risk of symptoms or disease has implications for the promotion of health in the workplace (stopping smoking) and employment. Further studies are required to establish the effects of endotoxin in isolation to dust and to determine the relation between reported symptoms and disease. With this information, valid exposure limits for organic dusts and endotoxin either specific to or independent of certain industries can be determined.

1 Chan-Yeung M, Malo JL. Aetiological agents in occupational asthma. Eur Respir f 1994;7:346-71.

2 Campbell JM. Acute symptoms following work with hay. BMF 1932;3:1143.
3 Becklake MR. Chronic airflow limitations: its relationship to work in dusty occupations. Chest 1985;88:608-17.

4 Niven RMcl, Fletcher AM, Pickering CAC, et al. Chronic bronchitis in textile workers. Thorax 1997;52:22-7.

5 Rask-Andersen A. Pulmonary reactions to inhalation of mould dust in farmers with special reference to fever and alveolitis [doctoral thesis]. Uppsala, Sweden: Uppsala University, 1988.

6 Rietschel ETh, Brade H, Brade L, et al. Newer aspects of the chemical structure and biological activity of bacterial endotoxins. In: Wten CJ. Bacterial endotoxins: structure, bioendotoxins. In. Wten CJ. Bacterial endotoxins: structure, biomedical significance, and detection with the limulus

7 Rylander R, Bake B, Fischer JJ, et al. Pulmonary function and symptoms after inhalation of endotoxin. Am Rev Respir Dis 1989;140:981-6.

8 Michel O, Ginanni R, Le Bon B, et al. Inflammatory response to acute inhalation of endotoxin in asthmatic patients. Am Rev Respir Dis 1992;146:352-7.

9 Kennedy SM, Christiani DC, Eisen EA, et al. Cotton dust and endotoxin exposure - response relationships in cotton textile workers. Am Rev Respir Dis 1987;135:194-200.

10 Editorial. Lancet 1978;i:249-50.

11 Rylander R. Role of endotoxins in the pathogenesis of respiratory disorders. European fournal of Respiratory Diseases Supplement 1987;154:136-44.

12 Michel O, Ginanni R, Duchateau J, et al. Domestic endotoxin exposure and clinical severity of asthma. Clin Exp Allergy 1991;21:441-8.

13 MRC. Committee on research into chronic bronchitis 1966 Questionnaire in respiratory symptoms and instruction for its use. London: MRC, 1966.

14 Fletcher AM. The prevalence of byssinosis and other work related symptoms in Lancashire cotton mills [M Phil thesis]. Manchester: Metropolitan University, 1993.

15 Simpson JCG, Niven RMcl, Pickering CAC, et al. Comparative exposures to endotoxin in workers exposed to organic dusts. Cotton and other organic dusts. Proceedings of the twentieth cotton and other organic dusts research conference, Beltwide Cotton Conferences. Memphis, TN: conference, Beltwide Cotton Conferences.
National Cotton Council, 1996:312-15.

16 Molfino NA, Wright SC, Katzi I, et al. Effect of low concentration of ozone on inhaled allergen responses in asthmatic subjects. Lancet 1991;338:199-203.

17 Fishwick D, Fletcher AM, Pickering CAC, et al. Respiratory symptoms and dust exposure in Lancashire cotton and manmade fibre mill operatives. Am $\mathcal{F}$ Respir Crit Care Med 1994;150:441-7.

18 Love RG, Smith TA, Gurr D, et al. Respiratory and allergic symptoms in wool textile workers. $\mathrm{Br} F$ Ind Med 1988;45:727-41.

19 Dosman JA, Cotton DJ, Graham BL, et al. Chronic bronchitis and decreased forced expiratory flow rates in lifetime non-smoking grain workers. Am Rev Respir Dis 1980;121:11-16.

20 Cotton DJ, Graham BL, Li KYR, et al. Effects of smoking and occupational exposure on peripheral airway function in young cereal grain workers. Am Rev Respir Dis 1982;126: $660-5$.

21 Marine WM, Gurr D, Jacobsen M. Clinically important respiratory effects of dust exposure and smoking in British coal miners. Am Rev Respir Dis 1988;137:106-12.

22 Ozesmi M, Aslan H, Hilderal G, et al. Byssinosis in carpet weavers exposed to wool contamined with endotoxin. $B r f$ Ind Med 1987;44:479-83.

23 Bringhurst LS, Byrne RN, Gershon-Cohen J. Respiratory disease of mushroom workers. $\mathcal{F} A M A$ 1959;171:101/15$104 / 18$ 